\title{
Descentramento e a busca de uma representação intersticial
}

\author{
Decentralization and the search for an interstitial representation
}

Descentralización y la búsqueda de una representación intersticial

Maria Tereza Amodeo ${ }^{1} 1$

Ilana Heineberg ${ }^{2} 2$

${ }_{1}^{1}$ Pontifícia Universidade Católica do Rio Grande do Sul, Porto Alegre, RS, Brasil.

${ }^{2}$ Université Bordeaux Montaigne, Pessac, França.

\section{A pairicion} palavra "centro" designa, na primeira definição do Trésor de la langue française, a situação espacial de um ponto interior, remetendo à ideia de meio e, por conseguinte, de simetria. A segunda acepção, que não pode ser rigorosamente separada da primeira, como observa o próprio dicionário, comporta a noção de movimento, de ação sofrida ou exercida. O centro constitui então, nas duas acepções, "o ponto ou elemento para onde convergem certas forças e/ou do qual emanam certos impulsos (ANALYSE ET TRAITEMENT INFORMATIQUE DE LA LANGUE FRANÇAISE, [2002], tradução nossa) ${ }^{1}$ ". Desse modo, por extensão, nomeia aquilo que é essencial ou fundamental, trazendo consigo uma noção de valor.

O contexto atual de "terceira mundialização" afeta profundamente a visão hierarquizada e centralista do mundo, agora considerada como "pós-colonial" ou "pós-europeia" pelas elites não europeias (MONGIN, 2007, p. 60). As produções teóricas e culturais vêm questionando, cada vez mais, a unanimidade, a validade e/ou a necessidade de um centro e vêm dando destaque à noção de descentramento. Cresce o interesse pela margem, pela periferia, pela diversidade, pela heterogeneidade e pela alteridade em detrimento de uma visão etnocêntrica, única, homogeneizadora e "monoidentitária". Os movimentos de convergência, os círculos em torno de um elemento e todo tipo de movimento centrípeto passam a ser vistos com desconfiança e a sua representação sofre processos de inversão e mudanças radicais de perspectiva. Isso porque o que caracteriza essa terceira fase da mundialização é o surgimento de um "duplo processo de unificação e fragmentação" (MONGIN, 2007, p. 57, tradução nossa) ${ }^{2}$. As reivindicações identitárias baseadas

\footnotetext{
Do original: L'idée dominante est celle d'un point vers lequel convergent certaines forces et/ou d'où émanent certaines impulsions.

2 Do original: un double processus d'unification et de fragmentation.
}

na etnia, na religião ou na civilização seriam, portanto, uma reação tanto a um mercado que homogeneíza os comportamentos, quanto à unificação tecnológica.

Movimento centrífugo, o ato de descentrar implica frequentemente uma dissociação, nem sempre fácil, entre o indivíduo e a sua própria perspectiva - que naturalmente tende a se confundir -, ou ainda uma renúncia desse mesmo indivíduo em ser ele próprio o centro. Nesse processo, podemos nos perguntar: o descentramento não tenderia a tornar-se um recentramento com todos os aspectos negativos e conformistas que isso comporta?

No que diz respeito à produção teórica, os Estudos Culturais, por terem uma ampla compreensão social e estética da cultura contemporânea, vêm exercendo um papel importante nesse processo de descentramento, fornecendo conceitos e ferramentas metodológicas para que o crítico possa se deslocar de uma posição hegemônica e adotar novas perspectivas que permitam captar o contemporâneo. Além disso, os Estudos Culturais têm se interessado por fenômenos e manifestações artísticas até então ignorados tanto pela academia, por não serem canônicos, como também por outras instituições, como editoras, museus, festivais, salas de espetáculo e outros espaços artísticos. Segundo Giorgio Agamben, a própria definição de contemporâneo, aqui no sentido de coetâneo, passa pela ideia de uma "certa defasagem" (AGAMBEN, 2008, p. 11, tradução nossa) ou de uma capacidade de "ver nas trevas" (AGAMBEN, 2008, p.20, tradução nossa), ou seja, a disposição de captar o seu próprio tempo exige, para Agamben, o descentramento do artista.

Um dos conceitos de maior fortuna crítica que ilustra esse movimento de descentramento é o de "entre-lugar", forjado por Silviano Santiago no texto "O entre-lugar do discurso latino-americano", escrito em 1971, e publicado pela primeira vez em 1978 na coletânea Uma literatura 
nos trópicos: ensaios sobre a dependência cultural. O título e o subtítulo do livro subentendem que há uma subversão de lugares quando se traz a "literatura" para os "trópicos". Silviano Santiago associa o "entre-lugar" ocupado pelo escritor latino-americano a um espaço de antropofagia cultural, de "devoração", marcado pela ideia de contaminação: "uma mistura sutil e complexa entre o elemento europeu e o elemento autóctone - uma espécie de infiltração progressiva efetuada pelo pensamento selvagem, ou seja, abertura do único caminho possível que poderia levar a descolonização" (SANTIAGO, 2000, p. 15).

Fica evidente, portanto, que processos de imposição de uma cultura hegemônica - como foi o caso da colonização, hoje de certa forma substituída pelos mecanismos de dominação cultural da era digital resultam em um movimento contrário de valorização do lugar discursivo do Outro e de novas estratégias enunciativas, daí a importância do debate sobre o lugar de fala e representatividade hoje no Brasil (RIBEIRO, 2017; DELCASTAGNÈ, 2013) que ultrapassa o âmbito acadêmico. Quando, em 2004, Silviano Santiago propõe o termo "cosmopolitismo do pobre" para pensar os efeitos da globalização junto à maioria pobre da população mundial, ele pretende justamente "colocar em evidência os paradoxos da mundialização atual por meio de um deslocamento para as margens" (HEINEBERG, 2018, p. 28, tradução nossa). ${ }^{3}$

O conceito de Silviano Santiago apareceria ligeiramente modificado em textos de inúmeros teóricos ao longo dos anos 1990. ${ }^{4}$ A antecipação de Silviano Santiago e o fato de ser pouco citado por críticos culturais que não sejam brasileiros mostra que os Estudos Culturais também têm os seus "entre-lugares", ou a sua semiperiferia (para utilizarmos um termo mais próximo ao de Boaventura de Sousa Santos). Assim, nessa geopolítica dos Estudos Culturais revelam-se também "os jogos de poder que se estabelecem durante a circulação das teorias da periferia em direção ao centro" (HEINEBERG, 2018, p.30, tradução nossa). ${ }^{5}$

\footnotetext{
3 Do original: mettre en évidence les paradoxes de la mondialisation actuelle à travers un déplacement vers les marges.

4 "Entre-lugar (S. Santiago), lugar intervalar (E. Glissant), tercer espacio (A. Moreiras), espaço intersticial (H. K. Bhabha), the thirdspace (revista Chora), in-between (Walter Mignolo e S. Gruzinski), caminho do meio (Z. Bernd), zona de contato (M. L. Pratt) ou de fronteira (Ana Pizarro e S. Pesavento), o que para Régine Robin representa o hors-lieu, eis algumas entre as muitas variantes para denominar, na virada de século, as "zonas" criadas pelos descentramentos, quando da debilitação dos esquemas cristalizados de unidade, pureza e autenticidade, que vêm testemunhar a heterogeneidade das culturas nacionais no contexto das Américas e deslocar a única referência, atribuída à cultura europeia" (HANCIAU, 2005, p. 127). Podemos acrescentar a esse repertório o "border thinking", "pensamento de fronteira", proposto por Glória Anzaldúa (1987).

5 Do original: les enjeux de pouvoir lors de la circulation des théories e la périphérie vers le centre.
}

Professora de teoria da literatura e escritora, Paloma Vidal, em uma homenagem ao conceito de "entre-lugar" cunhado por Silviano Santiago quando esse completou 40 anos, analisa vários projetos artísticos recentes, inclusive a sua conferência performática Ne pas écrire ${ }^{6}$. Todos esses projetos se inscrevem na linhagem do "entre-lugar": "ancorados em um lugar e, como já dizia Montaigne, 'olham o mundo do lugar onde estão', mas também se deslocam rumo à tradição cultural ocidental europeia, forçando um 'deslocamento do olhar', da compreensão, da sensação, da escuta por parte desta última"7 (VIDAL, 2018, p. 141, tradução nossa). Paloma Vidal (2018, p. 145, tradução nossa) conclui que hoje o "entre-lugar" são "muitos entre-lugares":

Digamos que o Outro difere, multiplica-se, complexifica-se, mas permanece sendo uma responsabilidade para a Literatura e para a Arte, que devem enfrentar a diferença que é por vezes radical. A meu ver, essa é a questão central hoje: como criar uma poética e uma política da alteridade para poder suportar e acolher um Outro que não é o Outro confortável, o Outro com o qual nos identificamos, o Outro imaginado por nós mesmos. Como escrever a partir deste Outro ${ }^{8}$

João Almino, escritor e diplomata, também associa o descentramento à metáfora da antropofagia e propõe que esta seja lida atualmente como a proposta de um "universalismo descentrado":

Uma tal perspectiva, de abertura, não significa abdicar do nacional em detrimento do universal, do local em detrimento do global, pois se o universalismo pode ser visto como uma invenção eurocêntrica, a universalidade não tem centro. Embora desigual e assimetricamente, valores, ideias, expressões culturais e costumes - nacionais e locais - migram, farão isso mais frequentemente com a maior facilidade das comunicações e sempre terão o potencial de universalizar-se (ALMINO, 1999, p. 47).

Já a crítica cultural chilena Nelly Richard que, ainda nos anos 1990, tomou posições críticas em relação ao

\footnotetext{
6 Apresentada no dia 14 de abril de 2016 na Université Bordeaux Montaigne.

7 Do original: quelques projets artistiques qui sont ancrés dans un lieu et qui, comme le notait déjà Montaigne, regardent le monde à partir du "pays où ils sont"; mais qui, à la fois, se déplacent, allant vers la tradition culturelle occidentale et européenne, et du même coup forcent un "déplacement du regard", de la compréhension, de la sensation, de l'écoute de la part de cette même culture.

8 Do original: Disons que l'Autre diffère, il se multiplie, se complexifie, mais reste une responsabilité pour la Littérature et pour l'Art, qui doivent faire face à la différence, parfois radicale. À mon avis, c'est la question centrale aujourd'hui: comment créer ne poétique et une politique de l'altérité pour pouvoir supporter et accueillir un Autre qui n'est pas l'Autre confortable, l'Autre avec lequel on s'identifie, l'Autre imaginé par nous-mêmes. Comment écrire à partir de cet Autre-là?
} 
Pós-modernismo, próximas às de Frederic Jameson, chama atenção para os perigos do que ela chamou de "centro-marginalidade pós-moderna", ou seja, a proposta de descentramento multiculturalista: "O pluralismo do Outro exibido pelo discurso pós-moderno se oficializou em uma retórica da 'diferença' que serve para muitos latino-americanistas do Centro sobretudo para prestarem um tributo - embora bastante cosmético - ao "marginal""9 (RICARD, 1995, p. 59, tradução nossa). Ou seja, para a crítica cultural chilena, a operação de descentramento que visa a evitar o antagonismo centro-periferia acaba por criar funções-centro, instâncias normativas ou canônicas que fazem girar em torno de si todo um sistema de referências (RICHARD, 1995, p. 57).

Outra maneira de chamar atenção para as operações de descentramento é interpretar ao pé da letra proposta ideia por meio de uma inversão radical da perspectiva cartográfica visual. Bertrand Westphal, autor de La cage des méridiens (2016), dedicou-se a estudar inúmeros exemplos de mapas invertidos do continente americano, a começar pelo famoso quadro de mesmo nome do pintor uruguaio Joaquín Torres García. Segundo Bertrand Westphal, a literatura tem por vocação enriquecer os espaços do real e por isso cabe a ela definir o possível (WESTPHAL, 2018, p. 45).

A produção artística contemporânea reflete esse movimento centrífugo ao mesmo tempo em que oferece a possibilidade de pensar a sociedade não mais de acordo com a oposição centro/periferia, mas de uma maneira mais matizada. A ficção integra os fluxos, as identidades híbridas ou o cosmopolitismo que circulam nessa sociedade. A ficção pós-moderna já havia começado essa mudança de perspectiva ao oferecer, de acordo com a expressão de Linda Hutcheon (1991), uma visão excêntrica da História na metaficção historiográfica, sobretudo através da valorização de personagens ou narradores ex-cêntricos em termos de classe, orientação sexual ou etnia.

O escritor argentino Ricardo Piglia, em um texto publicado pela primeira vez em 2001, aposta justamente na estratégia ideológica e enunciativa do descentramento para a literatura do próximo milênio. É assim que ele completa as cinco propostas de Ítalo Calvino, defendendo o deslizamento, o deslocamento e a mudança de lugar. "Sair do centro, deixar a linguagem falar das bordas, a partir do que escutamos e daquilo que nos chega do outro"10 (2013, p. 3), convida Piglia.

\footnotetext{
9 Do original: El pluralismo de lo Otro exhibido por el discurso postmoderno se ha oficializado en una retórica de la "diferencia" que principalmente les sirve a muchos de los latinoamericanistas del Centro para rendirle tributo - más bien cosmético - a lo "marginal".

${ }^{10}$ Do original: Salir del centro, dejar que el lenguaje hable también en el borde, en lo que se oye, en lo que llega de otro.
}

A questão do descentramento nas literaturas de língua portuguesa e, mais particularmente, a brasileira têm reunido pesquisadores do Departamento de Estudos Lusófonos e do Master Études Culturelles, da Université Bordeaux Montaigne, e da Pós-Graduação em Letras da PUCRS. Graças a um acordo de intercâmbio acadêmico, as instituições têm promovido conferências, minicursos, seminários, colóquios e publicações sobre literatura periférica feminina, representações da domesticidade na França e no Brasil, literaturas afrodescendentes e ruptura de estereótipos, entre outros. O objetivo dessas ações é promover, no Brasil e na França, espaços intersticiais capazes de estimular o descentramento de textos, autores, artistas, teóricos e obras.

Este número da revista Letras de hoje, dando continuidade a essa parceria, propõe-se a discutir as formas e os efeitos do descentramento na ficção contemporânea. Como as artes em geral e a literatura mais particularmente têm representado e traduzido tanto o descentramento do indivíduo nas sociedades contemporâneas quanto os indivíduos descentrados? Como a teoria tem acompanhado essas práticas? Quais as implicações formais do descentramento? Como a produção artística, através de práticas metaficcionais, teoriza o descentramento?

São essas algumas questões a que os textos reunidos nesse volume procuram responder. $\mathrm{O}$ primeiro grupo, composto por três artigos, segue um caminho mais teórico, refletindo sobre as operações de descentramento, seja do sujeito pós-moderno, seja do cânone literário. Segue-se a tais reflexões teóricas uma série de estudos de casos de narrativas brasileiras e estrangeiras, que utilizam a estratégia do descentramento, focalizando elementos ou temas caros ao narrar literário, tais como: o limite entre gêneros, os tipos de narrador, a escrita de si, a condição da mulher, a releitura de clássicos, a relação entre literatura e história. A esses doze artigos de pesquisadores brasileiros e estrangeiros, associam-se duas resenhas - uma de um texto crítico e outra de um romance - e uma tradução, com temas de certa forma afins ao dossiê proposto para essa edição.

O primeiro artigo, de autoria de Wibsson Ribeiro Lopes, que tem por título "Pós-modernismo, descentramento do sujeito e mapeamento cognitivo em Fredric Jameson", ao recuperar o diagnóstico do pós-modernismo construído por Fredric Jameson, apresenta um interessante panorama que contribui para a reflexão acerca da cultura e da arte no século XXI.

O tema do descentramaento na contemporaneidade, então voltado para o contexto brasileiro, é desenvolvido por Rejane Pivetta de Oliveira em "Deslocamentos antropofágicos na literatura marginal-periférica", que afirma a persistência da antropofagia na compreensão da literatura marginal periférica como fenômeno cultural 
integrado à dinâmica do sistema literário do país. Ressalta a necessidade de um exame cuidadoso da produção literária em questão, que possui estratégias de construção da alteridade, assim como conflitos e tensões envolvidos na ocupação do lugar de fala pelo sujeito marginal.

Também a partir do corpus da literatura brasileira contemporânea, em "Literatura e cidade rizomáticas", André Natã Mello Botton recupera o conceito de rizoma de Delleuze e Guattari, (1995), investindo na ideia de que literatura e cidade, concebidas como expressões rizomáticas, realizam-se como dimensões, direções movediças, que permitem que outros rizomas surjam, concebidos como agenciamentos em conexão às multiplicidades próprias de cada conceito.

Como a seção seguinte inclui estudos de obras específicas da literatura brasileira, elegeu-se, para iniciá-la o artigo "A escrita descentrada de Carolina Maria de Jesus", porque Luciana Paiva Coronel identifica, no antológico "diário de uma favelada", importantes estratégias enunciativas de descentramento. Para tais confluem aspectos históricos e institucionais que dialogam com o conceito de "poética de resíduos" de Raffaella Fernandez (2015), que consiste na mescla de estilos literários desterritorializados, muitas vezes em atrito e sem síntese possível no seu interior.

A perspectiva da voz da mulher, neste caso como foco do estudo, é analisada na sua condição frente a conflitos e interdições impostas socialmente, por Livia Maria Rosa Soares e Vilmaria Chaves Nogueira em "Identidades em trânsito: uma análise da representação feminina nos contos 'Os sapatinhos vermelhos' nas versões de Andersen e Caio Fernando Abreu”, contos publicados em um intervalo de 143 anos. A comparação entre os contos permite também a análise do fantástico na pós-modernidade, porque se relaciona, dentre outros, ao esfacelamento do sujeito, às identidades marcadas pelo duplo e o esmaecimento dos afetos.

Em "Narradoras excêntricas em Uma duas: a escrita como subsídio à construção da subjetividade feminina no romance de Eliane Brum", de Natacha dos Santos Esteves e Wilma dos Santos Coqueiro, as conarradoras constituem o foco do estudo, na medida em que, com suas narrativas viscerais e dilaceradas diante do mundo caótico marcado por profundas disparidades entre homens e mulheres, investem na escrita de suas memórias, purgando-se pelo efeito catártico, o que lhes permite viver suas subjetividades.

No tocante à representação de mulheres, o artigo de Barbara dos Santos "L'image de la femme dans A cabeça de Salomé d'Ana Paula Tavares" oferece uma análise baseada na imagologia, tendo em vista a sociedade angolana e a maneira como a obra integra o paradigma pós-colonial.
As marcas da constituição do sujeito no século XXI podem ser evidenciadas, segundo Maisa Barbosa da Silva Cordeiro e Eloiza Fernanda Marani, no artigo "Mongólia, de Bernardo Carvalho: o descentramento do narrador na ficção contemporânea", através de a composição tríade do foco narrativo da obra, que evidencia o caráter não autoritário do modo de narrar contemporâneo, composto por vozes distintas.

A margem no sentido da voz enunciativa e discursiva percebida fora do centro, ou seja, fora dos limites do discurso dominante histórico-político, constitui-se o foco do artigo de Alexandre Luiz Ribeiro da Fonseca Júnior "O recurso ao diário em $A$ noite da espera, de Milton Hatoum: o desenho de um conflito pessoal e de um conflito histórico-político", em que a escrita de si é entendida como espaço de autoconhecimento, de autorreflexão e de resistência.

Em uma viagem por Roma, Igiaba Scego em Roma negata, Percorsi postcoloniali nella città visita as suas raízes culturais maternas. Concentrando a atenção nos corpos e monumentos humanos da cidade, imprime uma abordagem ética que tem por objetivo informar os italianos sobre a obstinação de uma herança colonialista, conectando, de forma sensível, o tempo colonial ao presente atual da Itália. Euma perspectiva pós-colonial, o artigo "Roma negata d'Igiaba Scego: le nomadisme éthique d'une écrivaine migrante", de Martine Bovo, presente nesta edição, analisa o ensaio da escritora italiana de origem Somália.

Amélie Florenchie, em "Experiencias caoticas del descentramento em la narrativa de Juan Francisco Ferré”, questiona a visão crítica do escritor espanhol Juan Francisco Ferré acerca de seu país e da globalização presente em seus romances que evidenciam a ligação da Espanha ao seu passado de ouro, vinculada à concepção de modernidade fundada no binômio imperialismo/ colonialismo, problemático em um mundo globalizado.

Em "Tramas de museo en la novela y el documental argentinos: una lectura de Museo de la Revolución (2006) de Martín Kohan y El Predio (2010) de Jonathan Perel", Cecilia Gonzalez Scavino analisa dois produtos culturais - o romance e o documentário -, que, embora possuam formatos diferentes, propõem uma visão renovada, que exibe as "costuras" da história e desperta reflexões que questionam indiretamente a construção narrativa do passado.

A segunda edição da obra Negritude e literatura na América Latina, de Zila Bernd - publicada após trinta anos da primeira edição - enseja a resenha "Negritude e literatura negra como atos de conhecimento e de ação", de Cleusa Maria Gomes, que ressalta a relevância da obra por tratar da construção de uma identidade negra na poesia caraíba, latino-americana e brasileira e de aportes fundamentais para as discussões emergentes relativas ao 
tema até os dias de hoje, em que o número de escritores e escritoras afrodescendentes aumentou significativamente.

Analice de Oliveira Martins, ao contribuir com sua resenha “"Nas estradas do exílio': o sertão de Ronaldo Correia de Brito", analisa o romance de Ronaldo Correia de Brito Dora sem véu, publicado em 2018, que, dando seguimento ao seu projeto ficcional, traz um sertão nordestino atravessado por deslocamentos e embates de ordem diversa, em que se confrontam tradição e modernidade, localismo e cosmopolitismo, centro e periferia, fixidez e desenraizamento.

Encerra esta edição a tradução de Lauro Gomes do artigo de Marion Carel e Dinah Ribard "Testemunhar em poesia: o caso de Marc de Larréguy", que se propõe comprovar que os poemas em análise, construídos no front da Primeira Guerra Mundial, parecem testemunhar, não porque são testemunhos, mas porque dizem ser testemunhos, evidenciando que o valor ilocutório é apenas pretendido.

Buscando discutir sobre as formas e os efeitos do descentramento na ficção contemporânea, os artigos presentes nesta edição, assim como as resenhas e a tradução que se somaram a eles, deixam em evidência o contexto atual da mundialização, que afeta profundamente a visão hierarquizada e centralista do mundo. As narrativas de ficção contemporâneas problematizam, desacomodam essa tradição, em um tempo em que a "humanidade vive uma forma de exílio ontológico, cujo ser completo padece profundamente, até em sua voz e em sua palavra, ou até em sua alma, cortada do território interior onde ela se nutria" (OUELLET, 2013, p. 146). Nessa acepção, exílio significa mais do que uma imagem que pode traduzir, segundo Ouellet, a nossa relação com nosso tempo e o nosso espaço: diz respeito à condição do nosso imaginário. E, nessa perspectiva, "os seres de palavra" os escritores - são "agrimensores do mundo interior das línguas e das fábulas" (OUELLET, 2013, p. 147), como os estudos presentes nessa edição podem evidenciar.

\section{Referências}

AGAMBEN, Giorgio. Qu'est-ce que le contemporain? Paris: Rivages Poche, 2008.

ANZALDÚA, Glória. Borderlands - La Frontera: the new mestiza. Spinsters: Aunt Lute, 1987.

ANALYSE ET TRAITEMENT INFORMATIQUE DE LA LANGUE FRANÇAISE - CNRS \& Université de Lorraine. TLFi: Trésor de la langue Française informatisé. Disponível em: http://www.atilf.fr/tlfi. Acesso em: 9 nov. 2019. https:// doi.org/10.1108/09504120710755608

DALCASTAGNÈ, Regina. Literatura brasileira contemporânea: um território contestado.
HANCIAU, Núbia. Entre-lugar. In: FIGUEIREDO, Eurídice (org.). Conceitos de literatura e cultura. Rio de Janeiro: EdUFF, 2005. p. 125-141.

HEINEBERG, Ilana. L'entre-lieu des Études Culturelles au Brésil. In: AMORIM, Silvia, BOVO, Martine; HEINEBERG, Ilana. Visions décentrées des Études Culturelles. Ravenna: Giorgio Pozzi, 2018. p. 15-33.

MONGIN, Olivier. Le décentrement du monde. Esprit, p. 54-61, jun. 2007. https://doi.org/10.3917/espri.0706.0054

OUELLET, Pierre. Palavras Migratórias. In: HANCIAU, Nubia; DION, Sylvie (org.). A literatura na história. A história na literatura: textos canadenses em tradução. Rio Grande: Editora da FURG, 2013.

PIGLIA, Ricardo. Una propuesta para el próximo milenio. Cuadernos LIRICO, 9, p. 1-4, 2013, Disponível em: http:// lirico.revues.org/1101. Acesso em: 9 nov. 2019. https://doi. org/10.4000/lirico.1101

RIBEIRO, Djamila. O que é lugar de fala? Belo Horizonte: Letramento, 2017. https://doi.org/10.1590/s010471832019000200015

RICHARD, Nelly. La condición centro-marginal postmoderna. Travessia, Florianópolis, n. 29/30, p. 55-59, 1995.

SANTOS, Boaventura de Sousa. Entre Próspero e Caliban: colonialismo, pós-colonialismo e inter-identidade, Novos Estudos CEBRAP, n. 66, p. 23-52, 2003.

VIDAL, Paloma. Plusieurs lieux de l'entre-lieu. In: AMORIM, Silvia, BOVO, Martine \& HEINEBERG, Ilana. Visions décentrées des Études Culturelles. Ravenna: Giorgio Pozzi, p. 137-151, 2018.

WESTHPAL, Bertrand. La Cage des méridiens: la littérature et l'art contemporain face à la globalisation, Paris: Minuit, 2016.

WESTPHAL, Bertrand. Mapas invertidos. Les espaces américains sans dessus dessous. In: BERND, Zila; IMBERT, Patrick; OLIVIERI-GODET, Rita. Espaces et littératures des Amériques: mutation, complémentarité, partage. Laval: Presses Universitaires de Laval, 2018. p. 31-45.

Recebido em: 21/11/2019.

Aprovado em: 21/11/2019.

Publicado em: 21/12/2019.

Autoras:

Maria Tereza Amodeo

Doutora, Professora na Pontifícia Universidade Católica do Rio Grande do Sul, Porto Alegre, RS, Brasil.

Orcid: http://orcid.org/0000-0002-5039-4365

E-mail:mtamodeo@pucrs.br

Endereço: Av. Ipiranga, 6681 - Partenon

90619-900, Porto Alegre, RS, Brasil

ILANA HeINEBERG

Doutora, Professora na Université Bordeaux Montaigne, Pessac, França.

Orcid: http://orcid.org/0000-0002-4158-0115

E-mail: ilana.heineberg@u-bordeaux-montaigne.fr

Endereço: Domaine Universitaire, 19 esplanade des Antilles

33607 Pessac, França 